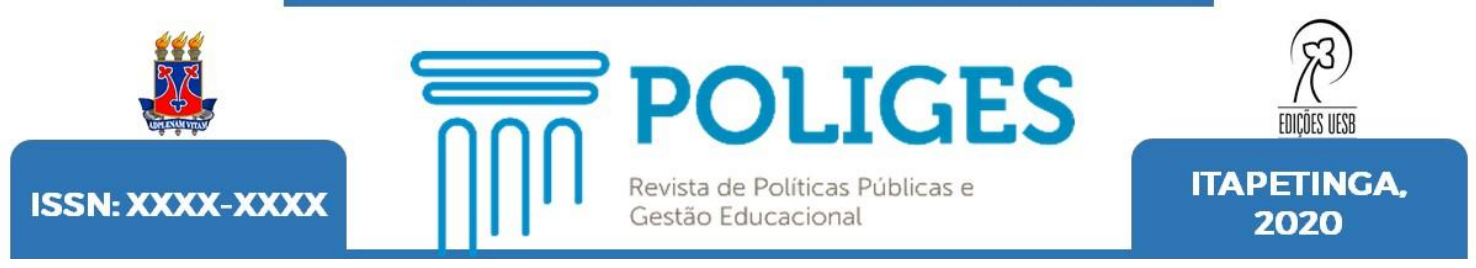

\title{
GESTÃO DEMOCRÁTICA DA EDUCAÇÃO SOB OS OLHOS E CORPOS DE JOVENS INTERNADOS PERANTE A LEI
}

\author{
DEMOCRATIC MANAGEMENT OF EDUCATION UNDER THE EYES AND BODIES \\ OF YOUNG PEOPLE INSTITUTIONALIZED UNDER THE LAW
}

\author{
LA GESTIÓN DEMOCRÁTICA DE LA EDUCACIÓN BAJO LA VISTA Y EL CUERPO \\ DE LOS JÓVENES INTERNACIONALES BAJO LA LEY
}

\begin{abstract}
Washington Luis de Andrade Cardoso Junior
ORCID iD: https://orcid.org/0000-0003-1020-2733 Doutorando em Ciências Sociais (UFBA) - SEMED/Lauro de Freitas - Brasil

Maria Couto Cunha

ORCID iD: https://orcid.org/0000-0002-2081-7232 Doutora em Educação (UFBA) - PPGE/UFBA - Brasil
\end{abstract}

\begin{abstract}
Resumo: Este artigo é parte do resultado de uma dissertação de mestrado que estudou a gestão democrática e o direito à educação em escolas públicas inseridas em Unidades de Internação, pesquisa desenvolvida em um programa de Pós-Graduação em Educação. A investigação partiu de uma inspiração marxista, tendo como referenciais teóricos os conceitos de hegemonia de Gramsci (1968), de Aparelhos Ideológicos do Estado, de Althusser (1985) e a docilidade dos corpos, de Foucault (1999). Seu objetivo foi, além de um estudo sobre a legislação que normatiza a oferta de educação escolar para a população jovem submetida a medidas restritivas de liberdade, analisar as percepções dos sujeitos inseridos em duas escolas vinculadas a um sistema municipal de ensino e dos demais profissionais das unidades de internação (gerentes, professores, educadores sociais, alunos) localizadas em Comunidades de Atendimento Socioeducativo de Internação (CASE), sobre os limites e possibilidades da Gestão Democrática nessa realidade educacional singular. O presente texto faz um recorte dos resultados da pesquisa de campo realizada sobre tais percepções. Os resultados apontam as dificuldades encontradas nas duas escolas pesquisadas de se exercitar a gestão democrática nos moldes como este princípio é colocado na legislação educacional vigente e na literatura pertinente desse campo do conhecimento, mesmo que alguns depoimentos dos colaboradores da pesquisa mostrassem possibilidades da efetivação de alguns indicadores dessa modalidade de gestão.
\end{abstract}

Palavras-chave: Gestão democrática. Juventude. Socioeducativo

Abstract: This article is part of the result of a master's thesis that studied democratic management and the right to education in public schools inserted in inpatient units, a 
research developed in a Postgraduate Program in Education. An investigation started from a Marxist inspiration, having as theoretical references the concepts of hegemony by Gramsci (1968), by Ideological Apparatus of the State, by Althusser (1985) and the docility of bodies, by Foucault (1999). Its objective was, in addition to a study on the legislation that regulates the provision of school education for the young population submitted to restrictive measures of freedom, analyzing the perceptions of the subjects inserted in two schools linked to a municipal education system and of the other professionals of the schools. Juvenile deliquency units (managers, teachers, social educators, students) present in International Socio-Educational Service Communities (CASE), on the limits and possibilities of Democratic Management in this unique educational reality. The present text makes an excerpt of the results of the field research carried out on such perceptions. The results point out the difficulties found in the two schools surveyed in exercising democratic management along the lines that this principle is applied in the current legislation and in the pertinent literature of this field of knowledge, even though some testimonies from the research collaborators showed possibilities for the effectiveness of some indicators. this type of management.

Keywords: Democratic management. youth. socio-educational

Resumen: Este artículo es parte del resultado de una tesis de maestría que estudió la gestión democrática y el derecho a la educación en las escuelas públicas insertadas en unidades de internación, una investigación desarrollada en un Programa de Postgrado en Educación. La investigación partió de una inspiración marxista, teniendo como referentes teóricos los conceptos de hegemonía de Gramsci (1968), de Aparato ideológico del Estado, de Althusser (1985) y la docilidad de los cuerpos, de Foucault (1999). Su objetivo fue, además de un estudio sobre la legislación que regula la provisión de educación escolar para la población joven sometida a medidas restrictivas de libertad, analizar las percepciones de los sujetos insertados en dos escuelas vinculadas a un sistema educativo municipal y de la otros profesionales de las escuelas Unidades de internación (gestores, docentes, educadores sociales, estudiantes) ubicadas en Comunidades de Servicios Socioeducativos de Internación (CASE), sobre los límites y posibilidades de la Gestión Democrática en esta realidad educativa única. El presente texto hace un extracto de los resultados de la investigación de campo realizada sobre tales percepciones. Los resultados señalan las dificultades encontradas en las dos escuelas encuestadas para ejercer una gestión democrática en la línea en la que este principio se ubica en la legislación educativa vigente y en la literatura pertinente de este campo del conocimiento, aunque algunos testimonios de los colaboradores de la investigación mostraron posibilidades. de la efectividad de algunos indicadores de esta modalidad de gestión.

Palabras clave: Gestión democrática. juventud. socioeducativo

\section{Introdução}

Este artigo é parte do resultado de uma pesquisa de mestrado com inspiração marxista, tendo como referenciais teóricos os conceitos de hegemonia de Gramsci (1968), de Aparelhos Ideológicos do Estado, de Althusser (1985) e da docilidade dos corpos, de Foucault (1999). Seu objetivo foi analisar as possibilidades e limites para a efetivação da gestão democrática em duas escolas do ensino fundamental 
inseridas em unidades socioeducativas de internação. A investigação teve como objetivos específicos: compreender a relação do ordenamento jurídico do Estado brasileiro com a responsabilização e imputabilidade penal ${ }^{1}$ da juventude; discutir a relação entre democracia e direito à educação dos jovens em privação de liberdade nos estabelecimentos de internação; e analisar as percepções dos sujeitos inseridos em duas escolas localizadas em Comunidades de Atendimento Socioeducativo de Internação (CASE) como uma realidade educacional singular. Este artigo faz um recorte sobre achados desse terceiro objetivo específico.

Procuramos pensar a democracia e, por consequência, a gestão democrática como um horizonte a ser alcançado na materialização do direito à educação que não se esgota na eleição direta e/ou em formas de consulta à comunidade escolar para o provimento dos cargos de direção das unidades escolares. A conformação de Paro (2018) sobre o papel da educação - "atualização histórica do homem", transcende a perspectiva restrita da simples transmissão de informações - justificando o debate da qualidade em termos da disputa da consciência ética e política dos sujeitos. Nesses termos, concordamos com Paro (2018), ao considerar que a democracia é um referencial estruturante para a compreensão da ideia de qualidade na educação. A materialização do direito à educação e à garantia da qualidade passa necessariamente pela educação para a democracia, vista em sua radicalidade na participação e diálogo entre todos os segmentos envolvidos no processo educativo.

Inicialmente, realizou-se o levantamento e a análise de documentos legais relacionados à gestão democrática com potencial de eficácia e validade no sistema municipal de ensino. Com base nesse levantamento e nos procedimentos escolhidos para o levantamento dos dados, foram realizadas treze entrevistas semiestruturadas com sujeitos representativos dos segmentos engajados na escolarização dos alunos matriculados nas duas escolas. Para organizar o estudo e analisar o material coletado nas entrevistas foi utilizada a abordagem da análise de conteúdo proposta por Bardin (2011), com uma adaptação das categorias analíticas propostas por Souza (2019) no Índice de Gestão Democrática (IGD): Variável 1 - (V1). Forma de

\footnotetext{
1 A expressão imputabilidade penal, na linguagem legislativa, significa a relação entre a ação consciente dos/as autores/as de condutas delitivas e a capacidade do Estado realizar a intervenção penal correspondente.
}

Revista de Políticas Públicas e Gestão Educacional (POLIGES) - UESB-Itapetinga. ISSN: XXXXXX - ano 2020, vol. 1, n. 1, set. - dez. de 2020. 
provimento dos diretores escolares; Variável 2 - (V2). Existência e funcionamento dos conselhos escolares; Variável 3 - (V3). Existência e forma de elaboração do Projeto Político-Pedagógico; e Variável 4 - (V4). Ambiente democrático, que sintetiza as três primeiras variáveis. Considerando o espaço permitido para este artigo, nos concentramos na apresentação dos achados referentes a essas variáveis.

\section{Abordagens teóricas da pesquisa}

O trabalho é inspirado na compreensão materialista-histórica e dialética da realidade. Esse caminho interpretativo busca analisar a realidade a partir de um ponto material, conformado historicamente e entrelaçado de contradições. Isso converge para o uso complementar da abordagem gramsciana, em especial, a construção do consenso/coerção como forma da Sociedade Política (Estado) se relacionar com a Sociedade Civil. A inspiração materialista histórica e dialética é levantada não apenas como um recurso poético do texto, mas carrega uma abertura e convergência com elementos tradicionalmente distante da tradição marxista, como a caracterização dos dispositivos de controle dos corpos, "os corpos dóceis", na obra Vigiar e Punir de Michel Foucault, em paralelo com a formulação de Louis Althusser sobre as escolas e as prisões, como Aparelhos Ideológicos do Estado - AIE.

Freitag (1986) destaca que Althusser avança na conformação da "Escola" na condição de AIE, destrinchando seu funcionamento e apresentando limites claros para a tomada de consciência dos explorados, mas não aponta a gênese histórica desses limites, nem apresenta perspectivas para romper esse ciclo de dominação. A maneira como Althusser descreve a materialização da luta de classes pelo funcionamento dos AIE e os limites da ação transformadora, mesmo que abnegada de educadores comprometidos com as lutas populares, faz Saviani (2011) atribuir à análise de Althusser um horizonte de "luta de classes" sem luta e com uma classe submetendo completamente a outra, dada a rigidez e impossibilidade de reação.

No entanto, a observação de limites para as formulações de Althusser sobre os AIE não invalida ou diminui sua importância para entender o papel da ação ideológica dessas instituições sobre os indivíduos nas sociedades capitalistas. 
Assim, um estudo sobre unidades escolares em espaços de privação de liberdade (carcerário ou socioeducativo) implica na definição do caráter híbrido desses AIE que convergem para a ação ideológica da Escola e da Prisão. O desafio é perceber a gênese de sentidos entre esse AIE prisional/educacional para explorar a materialização, ou não, da gestão democrática.

A convergência não usual entre a inspiração marxista e o uso dos dispositivos de controle sobre os corpos, referenciado em Foucault, foi pensada a partir da definição que Poulantzas (2002) apresenta sobre o Estado não como um "mero anotador" da realidade econômica e social e, sim, como um "fator constitutivo da organização da divisão social do trabalho, produzindo permanentemente fracionamento-individualização social" (POULANTZAS, 2002, p.63).

O Estado contribui para fabricar essa individualidade por um conjunto de técnicas de saber (ciência) e de práticas de poder, a que Foucault chamou de disciplinas ("que se pode caracterizar em poucas palavras dizendo que são uma modalidade de poder para o qual a diferença individual é pertinente"), procedimento designado pelo termo normalização(...)" (POULANTZAS, 2002, p. 63-64).

Essa definição aponta como problema essencial para a teoria do Estado a "individualização do corpo social, solo originário das classes em sua especificidade capitalista" (POULANTZAS, 2002, p. 63-64). Nesse aspecto este autor demarca a importância de Foucault na sua análise materialista de certas instituições de poder, não apenas confirmando as assertivas da tradição marxista, como, também, enriquecendo-as em inúmeros pontos (POULANTZAS, 2002, p.65). É da gênese desses dois referenciais que buscamos entender os limites e possibilidades para a materialização da gestão democrática nesses espaços projetados para a privação de liberdade.

\section{Campo da pesquisa}

As duas escolas incluídas na pesquisa são unidades de ensino mantidas e gerenciadas por um governo municipal, inseridas em Comunidades de Atendimento Socioeducativo, administradas por uma fundação de atendimento social para crianças e adolescentes, órgão vinculado ao governo estadual. Essa situação de 
uma repartição pública municipal inserida em um espaço gerenciado pelo governo estadual é um desdobramento do inciso III, do artigo $4^{\circ}$ da Lei $N^{\circ} 12.594 / 2012$, que institui o Sistema Nacional de Atendimento Socioeducativo (SINASE), regulamenta a execução das medidas socioeducativas destinadas a adolescente que pratique ato infracional. Esse inciso estabelece dentro das competências dos governos estaduais: criar, desenvolver e manter programas para a execução das medidas socioeducativas de semiliberdade e internação. Dessa forma, o funcionamento das escolas municipais nas unidades de atendimento socioeducativo, gerenciadas pelo governo do estado, se dá por meio de convênio entre os entes federados. As duas escolas atendem a jovens entre 12 e 21 anos incompletos, tanto da capital do estado como de várias cidades do interior, em cumprimento de medidas socioeducativas de internação.

\section{Amostra e critérios de inclusão}

A seleção das duas escolas gerenciadas pela prefeitura e, portanto, circunscritas às determinações do sistema municipal de ensino como lócus da pesquisa não foi feita ao acaso. Ao focalizar duas realidades orientadas por um mesmo sistema de ensino, a análise dos dados coletados no campo de atuação dos sujeitos foi feita sob os mesmos determinantes legais, no que pese as realidades terem singularidades a serem consideradas na interpretação das informações.

Nesses termos, a escolha de duas escolas subscritas na rede municipal, ao mesmo tempo em que restringe as prescrições legais específicas consideradas na pesquisa a um sistema de ensino, amplia a possibilidade de análise das duas unidades de internação que abraçam um quantitativo amplo de jovens cumprindo Medida Socioeducativa de Internação (MSEI) no estado.

A fundação de atendimento à criança e ao adolescente acima referida é o órgão responsável pela gestão da política de atendimento ao adolescente em cumprimento das medidas socioeducativas de semiliberdade e internação no estado, de acordo com o que estabelece o Estatuto da Criança e do Adolescente - ECA (Lei 8.069/1990) e o Sistema Nacional de Atendimento Socioeducativo - SINASE (Lei 12.594/2012) - gerenciando um total de 10 (dez) Unidades, sendo 2 (duas) de 
atendimento inicial/custódia temporária, 3 (três) de semiliberdade e 5 (cinco) de Internação. Para o desenvolvimento da pesquisa detivemos em duas unidades de internação existentes na Capital do Estado, gerenciadas por essa fundação.

Como o trabalho tem o horizonte de analisar as possibilidades e limites da gestão democrática em unidades de internação, a escolha de escolas que atendem adolescentes em cumprimento de MSEI matriculados em escolas de uma mesma rede pública inseridas nas Unidades de Internação com maior quantidade de internados justifica o lócus dessa pesquisa. De acordo com as informações da central de vagas e regulação, consultadas ao tempo da realização da pesquisa das 4 (quatro) unidades de internação referidas, duas delas concentram em termos quantitativos a maior parte das vagas e dos adolescentes internados no estado.

Das 360 (trezentos e sessenta) vagas disponíveis para adolescentes cumprindo MSEI nas unidades 235 (duzentos e trinta e cinco vagas) estão alocadas nas duas CASE localizadas na capital do estado, totalizando $65,28 \%$ da capacidade real dos espaços da MSEI. Sobre o quantitativo de internos é relevante demarcar a concentração de jovens privados de liberdade nesses dois espaços de atendimento socioeducativo. Dos 555 (quinhentos e cinquenta e cinco) adolescentes cumprindo MSEI, 395 (trezentos e noventa e cinco), ou seja, 71,17\% jovens estavam internados nas duas unidades onde foi desenvolvida a pesquisa. De acordo com informações de 2019 presentes no site da Secretaria Municipal de Educação do lócus da pesquisa, a Escola 01 contava com 38 (trinta e oito) alunos matriculados e a Escola 02 contava com 87 (oitenta e sete) alunos matriculados.

As duas escolas possuem uma estrutura organizacional convencional de unidade de ensino da rede escolar: (com direção, coordenação pedagógica, corpo docente, corpo técnico administrativo, secretaria escolar) e um registro institucional próprio, garantindo amplas possibilidades para investigar a efetivação, ou não, do princípio constitucional da gestão democrática do ensino público.

\section{Instrumentos e procedimentos de coleta}

Cumpre ressaltar que em grande parte da pesquisa, o procedimento básico se constituiu em análise documental, especialmente no que concerne ao estudo do 
conteúdo da legislação, manifestação aparente dos dispositivos legais vigentes no Sistema Municipal de Educação do campo investigado e na literatura pertinente. Para conformar os caminhos da materialização da gestão democrática, a partir de uma pesquisa de campo, foram realizadas entrevistas semiestruturadas com 4 (quatro) dirigentes - as diretoras das duas escolas e os gerentes das duas unidades de internação - 4 (quatro) professores/as, 2 (dois) socioeducadores e 3 (três) alunos. ${ }^{2}$ Os três alunos entrevistados foram escolhidos de forma a contemplar todas as etapas de escolarização do ensino fundamental. Como a Escola 02 contava com 87 (oitenta e sete) alunos matriculados em turmas equivalentes aos ciclos do ensino fundamental (anos iniciais e finais), dois alunos foram entrevistados. A Escola 01 que só contava com 38 (trinta e oito) alunos matriculados em turmas correspondentes às séries iniciais do ensino fundamental teve um aluno entrevistado.

A seleção dos/as entrevistados/as foi feita pela compreensão da centralidade da percepção dos sujeitos inseridos nessa realidade sobre as possibilidades da efetivação da democracia em espaços projetados para o controle e disciplina sobre os corpos. Assumimos que para discutir a materialização, ou não, da gestão democrática nesses espaços seria imprescindível ouvir vozes representativas dos sujeitos inseridos na educação formal. Essa escolha apontou para 13 (treze) entrevistas de forma a contemplar segmentos e olhares distintos na escolarização desses jovens a quem tantos direitos foram negados.

Apesar de compreendermos a importância das vice-diretoras e coordenadoras pedagógicas na conformação da equipe pedagógica foi necessário restringir o número das entrevistas do segmento gestão às duas diretoras e aos gerentes das CASE, para respeitar o tempo institucional de duração do curso de mestrado e analisar com o devido cuidado as informações advindas dessa técnica de pesquisa, garantindo um equilíbrio entre o quantitativo de dirigentes escolares e gestores das Unidades de Internação, além de professores/as e alunos.

\footnotetext{
2 Para garantir a confidencialidade dos/as colaboradores/as da pesquisa as referências aos segmentos entrevistados foram pautadas em um único gênero com o conjunto das profissionais do magistério - pela maior representação feminina - nomeada de professoras 01,02 e 03 , já os servidores municipais que ocupam os cargos de direção escolar foram denominados de diretores 01 e 02.
} 


\section{Indicadores da pesquisa}

Ao analisar o direito à educação e a gestão democrática em Unidades de Atendimento Socioeducativo de Internação é preciso conformar os caminhos específicos desses espaços, delimitando os contornos para aferir o cumprimento, ou não, do marco legal. A negação da democracia sob a justificativa de se tratar de espaços de privação da liberdade vai de encontro a um princípio constitucional que se anuncia sobre toda a educação pública e dos marcos legais que protegem as crianças e adolescentes. É esperado que a tutela do estado sobre os/as adolescentes em Unidades de Internação e o contexto de privação da liberdade, no que pese a legislação conformar um horizonte pedagógico às medidas socioeducativas, imponha adequações a premissa da gestão democrática. Sob essa lógica a inexistência de um conselho escolar nas duas escolas e a não participação das mesmas no processo de eleições diretas para gestores escolares no sistema municipal de ensino já apresentam contornos singulares às realidades observadas.

Buscando atender ao objetivo deste estudo foram construídos referenciais para a análise do material coletado no conjunto das treze entrevistas sob a inspiração da construção de Souza (2019) sobre um Indicador de Gestão Democrática (IGD) e das formulações de Paro (2018) acerca das relações entre gestão, democracia e qualidade da educação. O uso desses referenciais foi feito a luz das especificidades das realidades analisadas - duas escolas do sistema municipal de ensino inseridas em Unidades de Atendimento Socioeducativo de Internação - conformando limites para a apropriação crítica dos referidos conceitos em uma pesquisa qualitativa com contornos exploratórios.

Assim, adaptamos as quatro variáveis do que compõe o Indicador de Gestão Democrática (IGD), desenvolvido por Souza (2019), já anunciadas no início deste texto. Conforme já mencionado na introdução deste artigo, atentando para o pensamento de Victor Paro, o princípio constitucional da gestão democrática deve articular e dar sentido a múltiplos fatores que dão vida e sentido à democracia no espaço escolar. Desta forma, o trabalho educativo tem no diálogo um caminho 
incontornável para que a educação cumpra sua função de "atualização histórica do homem" (PARO, 2018).

Tanto é assim que a maior proximidade de uma gestão escolar democrática não implica, necessariamente, em maiores notas nas avaliações institucionais, porém, a democratização da escola fustiga os atores e atrizes a um compromisso coletivo com a instituição e a buscarem saídas para os desafios cotidianos de um estabelecimento de ensino. Essa premissa aproxima e coloca as concepções anticapitalistas como uma consequência lógica da radicalidade dos princípios democráticos nos espaços de poder, incluindo a escola, à luz da superação histórica dos padrões de (re)produção das desigualdades. Em outras palavras, apesar de não ser a condição exclusiva, a gestão democrática é o ponto de partida para a materialização do direito à educação.

\section{Os principais achados da pesquisa de campo}

Vamos nos concentrar a partir daqui nas análises de algumas falas dos nossos entrevistados das duas unidades selecionadas, seguindo a sequência das variáveis escolhidas que possam denotar a existência do princípio da gestão democrática materializado nas escolas.

\section{Provimento dos cargos de Direção Escolar}

Apesar de a eleição direta e/ou consulta pública não garantir a materialização da gestão democrática, Sousa (2019) demarca que a bibliografia específica sobre o tema coloca a forma de provimento como o ponto de partida para a democratização de espaços de poder historicamente assimétricos como as direções escolares, já que a forma de provimento tem relação direta com o perfil de gestão escolar. Nesses termos é preciso resgatar duas interpretações sobre a função/papel que a eleição direta pode exercer em espaços de poder em um sentido amplo do conjunto das entrevistas realizadas. Ao observar as falas de alguns dos/as entrevistados(as) foram identificadas duas tendências a esse respeito que apontam elementos 
implícitos sobre os limites da democratização das unidades de internação sob a lógica dos segmentos envolvidos no atendimento socioeducativo: a potencialidade do processo eleitoral como forma de alternância dos quadros que ocupam os espaços de poder, de um lado, e a recusa da eleição direta por uma afinidade e/ou compromisso com o grupo que ocupa a direção escolar, de outro.

No primeiro grupo é possível identificar uma aproximação com a concepção majoritária de defesa do processo eleitoral com um recorte qualitativo dos/as candidatos/as aptos/as a participar da disputa.

Eu acho que sim e que, sendo que a escola é um instrumento público, era importante que as pessoas que são sujeitos do nosso trabalho deveriam avaliar. Nada mais democrático que se você pudesse dizer se o professor ou diretor fosse efetivamente aquele que contribuísse para realizar os anseios da escola, desde a portaria, da merendeira, todas as ações administrativas, do alunado. Seria bom que as pessoas pudessem falar sobre essa gestão e escolher profissionais que tenham a característica, dentro da legalidade, óbvio, e dos princípios de humanidade, uma relação bacana com os outros (GERENTE 01).

O Gerente da CASE-01 relaciona a eleição a uma avaliação coletiva e periódica do trabalho da gestão escolar, demarcando o respeito às premissas legais e peculiaridades de uma escola inserida em uma unidade de internação. A fala do gerente anuncia a participação de segmentos diversos da comunidade escolar na eleição/consulta, o que demonstra uma proximidade com as premissas estabelecidas pelo marco legal em vigor acerca das medidas socioeducativas de internação e a arquitetura institucional imposta pelo ECA.

O segundo grupo - não apoia a ideia da eleição direta para o gestor escolar. Isto, por uma afinidade e/ou compromisso com a direção escolar - tem relação direta com a concepção menos avançada sobre o processo eleitoral. Essa relação pode ser observada na proximidade da fala do Aluno $03 \mathrm{com}$ a do Diretor 01. "Eu acho que pode até ter, mas pelo que eu vejo a diretora da escola, ela dirige bem, todo dia está aqui e está resolvendo os pequenos problemas da equipe que é normal em todas as escolas" (ALUNO 03).

O depoimento do aluno demonstra sua posição contra a possibilidade da eleição/consulta como forma de provimento dos cargos de direção escolar, vista com a única função de substituir a diretora em caso de problemas no cotidiano da gestão. 
É possível inferir que essa percepção decorra da falta de experiências, nos ambientes que ele tem vivenciado, de escuta e participação por meio de mecanismos de "aprendizado coletivo" (SOUZA, 2009). O distanciamento dos alunos com questões relacionadas à democracia pode ser uma projeção do controle exercido sobre seus corpos (privação de liberdade) em convergência com um itinerário de vida sem nenhuma proximidade com os direitos fundamentais da Constituição Federal de 1988. Nesses termos, palavras como democratização, diálogo e participação estão completamente alheias ao universo de possibilidades de milhões de homens e mulheres que tem como horizonte imediato a busca pela sobrevivência diante de condições adversas. A ausência de um caminho de democratização das relações de poder faz com que os segmentos pauperizados (negros/periféricos) não vislumbrem o espaço público como um horizonte de disputa e materialização de direitos sociais e coletivos.

A tendência mais avançada sobre o mecanismo da eleição/consulta sem mecanismos restritivos foi expressa por dois entrevistados. Uma das professoras estabeleceu um paralelo interessante da participação dos adolescentes aptos a votar nas eleições mediante as urnas fornecidas pelo Tribunal Regional Eleitoral.

\begin{abstract}
Eu acredito que sim. Acho que se a gente tivesse o Conselho Escolar teríamos condição de ter eleição. Nós temos meninos com mais de quatorze anos que teriam perfeitamente condições de votar, até porque muitos deles já votam, na eleição formal, já que tem uma seção aqui e os meninos maiores de dezesseis votam. Acho que eles têm condição de votar até porque se a eleição for trabalhada de forma correta, eles teriam autonomia, sim, para escolher... (PROFESSORA 01).
\end{abstract}

Sua fala coloca os alunos da escola como ponto de partida para pensar o processo eleitoral. Ao ser questionada sobre como a equipe receberia a eleição direta para os cargos de Direção, ela minimiza possíveis problemas diante das tensões vivenciadas em outras escolas do Sistema Municipal de Ensino ante a disputa eleitoral. "Isso aí a gente nunca sabe. Mesmo nas escolas lá de fora, muitas vezes, esse processo eleitoral é tortuoso e conturbado" (PROFESSORA 01).

Um dos socioeducadores entrevistados acompanha a tendência mais avançada sobre o processo eleitoral demarcando o papel que a escola tem nas medidas socioeducativas e posterior mudança/transformação desse adolescente e 
que a eleição teria um papel importante no resgate de valores para a trajetória posterior à internação. Deve-se, no entanto, salientar que uma parte dos entrevistados optou por uma resposta intermediária, indicando a possibilidade do processo eleitoral nas duas escolas desde que os/as candidatos/as tivessem experiência e conhecessem a realidade do socioeducativo.

\section{Sobre a importância dos conselhos escolares para a gestão democrática}

A ausência de um conselho e/ou colegiado na escola é um entrave destacado no conjunto das entrevistas, tanto para a participação das duas escolas no processo de eleição para o provimento dos gestores escolares, quanto para a autonomia financeira, mediante utilização dos recursos diretos na unidade escolar. Os questionamentos aos entrevistados buscaram identificar como um Conselho poderia contribuir com a gestão da escola e a maneira como a unidade escolar procede para mitigar as lacunas geradas pela inexistência desse órgão colegiado.

As respostas sobre essa situação hipotética reproduziram aspectos abordados acerca de uma eventual eleição direta para os cargos de direção escolar, contanto que os/as candidatos/as tivessem um engajamento pessoal e experiência na educação formal em espaços de atendimento socioeducativo. Além do acesso às verbas destinadas à manutenção direta das escolas, autonomia financeira, que possuem esse espaço de controle social. Outro aspecto mencionado pelos informantes seria a possibilidade de institucionalizar decisões coletivas sob a legitimidade deste órgão colegiado.

As falas dos gerentes destacam o papel institucional que os conselhos poderiam exercer no cotidiano da gestão escolar, bem como a participação das famílias desses jovens nesse espaço de poder colegiado.

Ter um conselho, membros definidos, ações definidas poderia criar uma ação mais planejada e eu diria até estratégica na atuação tanto da operação da unidade quanto da escola. Os discursos também deixariam de ser muito do senso comum, tendo o conselho fiscalizando e acompanhando os caminhos e direcionamentos. (GERENTE 01) 
O Gerente da Unidade 2 também se posicionou sobre este assunto:

O colegiado é formado tanto de colaboradores, como também de pai de alunos. Uma das coisas que sempre falo aqui, trabalhar numa unidade de privação de liberdade (socioeducação) não funciona sem a presença dos pais, não. Os adolescentes estão aqui cumprindo medida socioeducativa, mas eles vão retornar para a família. "Nós somos a família deles", digo assim entre aspas, emprestados, nesse momento, mas eles vão retornar para a família deles. (GERENTE 02)

Quando se observam as falas sobre as possibilidades de um conselho na escola é possível identificar dois elementos que são coerentes às concepções educativas expostas pelos informantes ao longo das entrevistas: o compromisso coletivo com as demandas dos jovens internados nas CASE e a dificuldade de estabelecer critérios para a composição de colegiados, ante o caráter itinerante e temporário do alunado.

Se a escola possuísse um conselho ou um colegiado escolar, esse conselho ou colegiado escolar, não só aqui, como em qualquer unidade escolar tem que ser formado de pessoas que realmente estejam voltadas para a educação de jovens, porque o que se vê muito, hoje, é um descaso total dos conselhos e não se preocupam em buscar qualidade na parte pedagógica. Se tivesse um colegiado com compromisso com esses jovens, realmente seria melhor para a Escola. (DIRETOR 01)

$[\ldots]$

Acho que um Conselho é fundamental em qualquer espaço escolar. A gente observa que na gestão socioeducativa, (aqui dentro) temos dificuldade em tomar algumas decisões e algumas ações, por falta desse Conselho. A questão mesmo das verbas, por exemplo, depende muito da sensibilidade do órgão central para que a Escola tenha suporte pedagógico, e material. É uma coisa que tentamos implementar a alguns anos, mas por conta dessa clientela, que é itinerante não conseguimos instituir esse Conselho. O corpo docente é fixo, temos funcionários por determinado tempo, mas os alunos estão conosco hoje e amanhã podem não estar, os membros da família a mesma coisa (DIRETORA 02).

O segmento magistério aponta a instituição do conselho como um caminho de democratização do espaço escolar, além de abrir possibilidades para superar os entraves legais sobre o acesso às verbas destinadas à manutenção da escola que se projetam na ausência de recursos materiais para o trabalho pedagógico. 
Contribui para a gestão da escola. Na nossa escola o que a gente tem de material é precaríssimo, então, só por esse ponto aí, ele já valeria a pena ter um Conselho, porque, teríamos acesso a coisas que hoje a gente não tem. A gente pode pensar em questões de democratização do que acontece dentro da escola e fiscalização da direção. Então, são várias as possibilidades de um conselho ou colegiado escolar (PROFESSOR).

Como se vê, em todos os segmentos da unidade percebe-se os pontos de vista específicos para que a escola tenha um conselho escolar. Por outro lado, percebemos que o conceito de conselho escolar e a compreensão sobre as suas possibilidades como mecanismo de uma gestão democrática, demonstrados pelos sujeitos pesquisados são distantes dos pressupostos que a política educacional atual concebe-os, na perspectiva de tomadas de decisão da escola pelos vários segmentos, seja de cunho pedagógico, seja administrativo, seja político, conforme a literatura existente e a legislação pertinente apontam.

\section{Existência e forma de elaboração do Projeto Político-Pedagógico - PPP}

Outro aspecto analisado sobre as possibilidades de um ambiente democrático nas escolas tratou-se da existência e/ou participação da comunidade escolar na elaboração do Projeto Político Pedagógico (PPP). No debate sobre o PPP a sua existência e a análise do seu conteúdo não são mais importantes do que a forma como ele é produzido, levando em conta o envolvimento e a participação dos atores e atrizes da comunidade escolar na sua elaboração. Na contramão das expectativas gerais do PPP como um instrumento de democratização, construído coletivamente, os depoimentos colhidos na pesquisa ressaltam que esse dispositivo legal encontra pouca, ou nenhuma, aderência no cotidiano das duas escolas. As falas vão ao encontro da ideia distorcida, porém corrente, do PPP apenas como uma exigência formal, cuja única função é cumprir as determinações burocráticas da secretária de educação. Mesmo as falas sobre a reformulação do texto não apresentam perspectivas do envolvimento da maior parte dos/das profissionais das escolas.

Desta forma, as respostas dadas pela direção geral das duas escolas confirmam a existência do PPP, elaborado em um período anterior às suas gestões, 
e uma demanda explícita por parte da Secretaria da Educação para adequações no conteúdo dos textos para atender às especificidades da educação formal em Unidades de Internação. Mas que essas adequações se encontram em processo.

A escola possui um Projeto Político Pedagógico, que foi feito quando
da sua institucionalização. Ele foi feito com base na escola regular
normal e, como nós somos uma escola diferenciada, hoje nós
estamos reformulando esse PPP para dar uma caracterização,
relacionada ao socioeducativo. Na época que ele foi feito, eu não
estava na escola, mas eu acredito que tenha sido feito com a
participação dos colegas, dos professores e do grupo pedagógico
que lá estava, porque na gestão anterior, ela tinha o compromisso de
fazer uma gestão participativa. (DIRETORA) $[\ldots]$

Existe um projeto antigo e nós estamos trabalhando, agora, em um novo que dê mais ênfase ao socioeducativo para as duas escolas da rede municipal. (DIRETOR)

Ao descrever o processo de sistematização do novo PPP, o diretor e a diretora pontuam os esforços de criar momentos de escuta dos diversos segmentos que compõem o trabalho de educação formal nas unidades de internação como um desdobramento lógico da elaboração de referenciais curriculares próprios para as duas escolas inseridas em Unidades de Internação submetidas ao Sistema Municipal de Educação. No entanto, percebe-se que estas afirmações se situam mais no discurso e se referem a uma ação remotamente desenvolvida, ou pretensamente futura e lenta no processo de construção.

É necessário se escutar todos os segmentos, porque diz respeito, realmente, às ações pedagógicas e todo o contexto que envolve a dinâmica da escola, logo todos terão que ser ouvidos e dar a sua contribuição pedagógica e administrativa. (DIRETORA)

$[\ldots]$

Nós já fizemos três etapas onde quinzenalmente era realizada, em um espaço fora do ambiente escolar, uma reunião com todos os professores e funcionários, para discussão sobre o PPP. Por conta de demandas da escola, a outra fase de discussão interna na unidade escolar foi interrompida. (DIRETOR). 
Quando os professores/as são questionados sobre o PPP as respostas fazem oscilar entre o desconhecimento sobre a sua existência ou menções vagas sobre seu lançamento na fundação das escolas. A reformulação apontada pelo Diretor e pela Diretora não encontra entusiasmo na fala de dois dos três profissionais do magistério entrevistados, o que nos leva a crer que o engajamento na reformulação do documento não envolveu a maioria do corpo docente.

Falou-se do lançamento desse documento na fundação da escola. Foi escrito um Projeto Político Pedagógico e em algum tempo depois se falou da sua reformulação. Há alguns anos a SMED realizou atividades voltadas para a reformulação desse PPP, mas confesso que não sei em que pé anda. Recentemente se falou na reformulação. Não sei dizer se já está pronto, se foi concluído, fechou, se ainda está se adequando. (PROFESSORA 01)

$[\ldots]$

Não é do meu conhecimento que exista um Projeto Político e Pedagógico, mas me recordo de, agora, no segundo semestre ouvir da coordenação que a gente precisaria conversar sobre o projeto político pedagógico da escola. (PROFESSOR 03)

$[\ldots]$

Desde que eu entrei aqui já existe esse processo político-pedagógico, voltado para o socioeducativo. A metodologia ainda precisa ser melhorada, mas a fundamentação trás todos os teóricos com que a gente lida com no socioeducativo. Um grande avanço foi a aprovação das diretrizes das escolas municipais inseridas em unidades de atendimento socioeducativo de internação. (PROFESSORA 02)

Mesmo a professora que demonstrou maior engajamento com o processo de reformulação do PPP não teve acesso, nos seus oito anos de atuação na Unidade Escolar, ao conteúdo desse documento. O desconhecimento geral sobre o conteúdo do PPP é sintetizado pela "mea culpa" da professora 01 "Mas também não procurei" (PROFESSORA 01). O desinteresse sobre o documento aponta uma realidade onde o PPP serviu apenas para atender a cobranças institucionais, sem um sentido orgânico e funcional para a comunidade escolar. Como se vê, há uma situação confusa quando se indaga sobre a existência e sobre a elaboração participativa do documento. Podemos concluir que o PPP não tem sido, de fato, um componente da gestão democrática no contexto pesquisado, mas que as normas restritivas da 
unidade de internação não são empecilhos para que ele seja instrumento norteador da educação nas escolas e se tal instrumento deve contar com a participação da comunidade escolar, como pressuposto de gestão democrática. Estas informações fazem sugerir uma falta de coordenação e articulação da secretaria de educação do município em dar uma assistência mais direta à essas escolas.

\section{À guisa de conclusão}

Os dados coletados nesta pesquisa para além do recorte que trabalhamos neste artigo nos levam a considerar que a realidade singular das duas escolas municipais inseridas em Comunidades de Atendimento Socioeducativo de Internação (CASE) aponta para dilemas institucionais únicos de um equipamento público do município que está inserido em um espaço de privação de liberdade gerenciado pelo Governo do Estado. Essa complexa rede de atribuições de entes federados, com profissionais de vínculos de diversas naturezas (estatutários/Cargos Comissionados/Tercerizados) convive mediante tensões e conflitos no atendimento socioeducativo que impactam o funcionamento das escolas.

Mesmo assim, os depoimentos sobre as questões trabalhadas na pesquisa demarcam que as dificuldades são superadas pelo compromisso e esforço coletivo dos profissionais engajados com a educação formal, bem como os diversos setores das duas CASE. Mesmo com o impacto das questões de segurança na dinâmica educativa das duas escolas, é possível inferir nas falas uma tentativa de articular as ações vinculadas à escolarização e o trabalho da equipe de segurança, tanto para garantir um maior tempo de contato dos alunos com as aulas, como para mitigar os efeitos de suspensões eventuais das atividades pedagógicas no espaço escolar.

Dessa maneira foi observada, nos depoimentos, uma relação dialógica e propositiva na relação entre os/as professores/as e os alunos, bem como possibilidades cotidianas de atuação dos socioeducadores que transcendem as questões de segurança e alcancem uma função eminentemente educativa em uma aproximação evidente com os princípios educativos anunciados pela fundação responsável pelo funcionamento desses equipamentos. 
Ao analisar o direito à educação e a gestão democrática em Unidades de Atendimento Socioeducativo de Internação é preciso conformar os caminhos específicos desses espaços delimitando os contornos para aferir o cumprimento, ou não, do marco legal. A negação da democracia sob a justificativa de se tratar de espaços de privação da liberdade vai de encontro a um princípio constitucional que se anuncia sobre toda a educação pública e dos marcos legais que protegem as crianças e os adolescentes.

A não participação das escolas no processo de eleições diretas para o provimento dos cargos de direção que é promovido pelo Sistema Municipal de Ensino, a inexistência de um conselho escolar nas duas escolas e a não participação na elaboração e cumprimento de um projeto político pedagógico por parte da comunidade escolar apresentam contornos singulares às realidades observadas, mostrando a grande distância de se materializar o princípio da gestão democrática do ensino público nesses contextos, mesmo que alguns dos entrevistados tenham salientado a importância dessas categorias analíticas e as possibilidades de sua concretização no ambiente por eles vivenciado.

Assim, a inspiração no Indicador de Gestão Democrática (IGD) formulado por Souza (2019) na interpretação das informações presentes nas entrevistas foi feita sob a lógica de como as Escolas funcionam sem o Conselho Escolar e como as atribuições desse órgão colegiado são absorvidas pelos/as profissionais (direção escolar/corpo docente/corpo técnico-administrativo) e alunos/as. Dessas questões foram identificados elementos para conformar a confluência, ou não, de um ambiente democrático.

Outras informações colhidas na pesquisa matricial ampliam algumas análises que não puderam ser apresentadas neste artigo. No entanto, podemos concluir, a partir do recorte de informações aqui trabalhadas que o retrato do cotidiano fotografado no campo empírico apontou algumas potencialidades para a democratização da gestão, mesmo que a legislação imponha limites e a ação ideológica difusa sobre esse Aparelho Ideológico de Estado híbrido obstaculize o seu desenvolvimento. 


\section{Referências}

ALTHUSSER, Louis. Aparelhos Ideológicos de Estado: nota sobre os aparelhos ideológicos do Estado. 2.ed. Tradução: Walter José Evangelista e Maria Laura Viveiros de Castro. Introdução crítica José Augusto Guilhon Albuquerque, Rio de Janeiro: Edições Graal, 1985.

BARDIN, Laurence. Análise de Conteúdo. Tradução: Luís Antero Reto, Augusto Pinheiro. São Paulo: Edições 70, 2016.

BRASIL. Constituição da República Federativa do Brasil. 1988. Disponível em: http://www.planalto.gov.br/ccivil_03/constituição/constituição.htm. Acesso em: 12 dez. 2018.

BRASIL. Lei de Diretrizes e bases da Educação Nacional, Lei 9394, 20 dez. 1996. Estabelece as diretrizes e bases para educação nacional. Brasília. Disponível em: http://www.planalto.gov.br/ccivil_03/constituição/constituição.htm. Acesso em 12 dez. 2018.

BRASIL. Lei $\mathbf{n}^{\circ} \mathbf{8 0 3 5}$, de 20 de dezembro de 2010. Aprova o Plano Nacional de Educação para o decênio 2011-2020. Diário oficial da União, Brasília, DF, 20 dez. 2010.

BRASIL. Lei 12.594, de 18 de janeiro de 2012. Institui o Sistema Nacional de Atendimento Socioeducativo (SINASE). Diário Oficial da União, Brasília, 18 jan. 2012.

FREITAG, Bárbara. Escola, estado e sociedade. São Paulo: Moraes, 1986.

FOUCAULT, Michel. Vigiar e punir: nascimento da prisão. 20.ed. Tradução: Raquel Ramalhete. Petrópolis: Vozes, 1999.

GRAMSCI, Antonio. Os Intelectuais e a Organização da Cultura, Rio de Janeiro: Civilização Brasileira, 1968

PARO, Vitor. Henrique. Gestão Escolar, Democracia e qualidade do ensino. 2. ed. rev, São Paulo: Intermeios, 2018.

POULANTZAS, Nicos. O Estado, o poder, o socialismo. São Paulo: Paz e Terra, 2002.

PROJETO POLÍTICO PEDAGÓGICO. Escola Municipal Professor Carlos Formigli.12p. Salvador, [201-]. SALVADOR. Lei Orgânica do Município do Salvador. Câmara Municipal de Salvador. 5 de abril de 1990. Disponível em: http://www.cms.ba.gov.br/uploads/LOM001.pdf. Acesso em: 12 mar. 2019.

SALVADOR. Lei Complementar n³6. Estatuto do Magistério. Câmara Municipal de Salvador. 30 de abril de 2004. Disponível 
em:https://leismunicipais.com.br/estatuto-do-magisterio-salvador-ba. Acesso em: 12 mar. 2019.

SALVADOR. Decreto $\mathbf{n}^{\circ}$ 30.118. Prefeitura Municipal de Salvador. 29 de agosto de 2018. Disponível em: https://leismunicipais.com.br/estatuto-domagisterio-salvador-ba. Acesso em: 12 mar. 2019.

SAVIANI, Dermeval. Pedagogia Histórico-Crítica: Primeiras Aproximações. Campinas: Autores Associados, 2011.

SOUZA, Ângelo. Ricardo, de. As condições de democratização da gestão da escola pública brasileira. Revista Ensaio: avaliação das políticas públicas em Educação. Rio de Janeiro, v.27, n.103, p. 271-290, abr./jun. 2019.

SOUZA, Jessé de. A Ralé Brasileira: quem é e como vive. Belo Horizonte: Editora UFMG, 2009.

\section{Washington Luis de Andrade Cardoso Junior}

Possui Licenciatura em História pela Universidade Federal da Bahia, com Mestrado em Educação pela mesma Universidade. Atua como professor de História nas Redes Municipais de Ensino de Salvador e Lauro de Freitas. Tem experiência em pesquisas relacionadas às políticas educacionais e gestão escolar. Na condição de Diretor de Assuntos Educacionais do ASPROLF-SINDICATO, entidade sindical que representa os trabalhadores/as da Rede Pública Municipal de Lauro de Freitas, acompanha as atividades dos espaços de controle social, em especial do Conselho Municipal de Educação, como suplente do segmento da representação docente.

\section{Maria Couto Cunha}

Possui Doutorado em Educação pela Universidade Federal da Bahia, UFBA, Mestrado em Educação pela Universidade Federal da Bahia, UFBA, Especialização em Metodologia do Ensino Superior, pelo Centro de Estudos de Pós Graduação Olga Mettig, CEPOM, Graduação em Bacharelado em Ciências Sociais, pela Universidade Federal da Bahia, UFBA, Graduação em Licenciatura em Ciências Sociais, pela Universidade Federal da Bahia. Professora do Programa de Pós-Graduação em Educação da UFBA, atuando nas áreas da Política, Gestão da Educação e formação de professores da educação básica. 